by techniques based on absorption, but the cost and maintenance of apparatus of this type make their use impracticable.

During the course of several months, usage of this system has proved satisfactory, and we regard this as an acceptable technique for the removal of oil contamination. Though the filters do not appear to be passing detectable oil after several months' use, it seems reasonable to change the filter elements, costing about 30 s. each, at quarterly intervals.

\section{Summary}

Patients in an intensive therapy unit were being directly ventilated with air from a piped system. It was suspected that this air could be contaminated by oil mist from the compressors used in the system.

By passing the compressed air through a collection device, it was possible to extract oil in microgram quantities, which were subsequently estimated by spectrofluorimetry. Oil contamination was studied under various working conditions.

Because of the implication of oil mist contamination, successful modifications were made to the air-supply system. Even when collections have been made for several days, oil contamination is now below the level of detection.

We would like to acknowledge the co-operation of the British Oxygen Company, and in particular Messrs. J. Cartwright and V. Owen, who have shown the greatest interest in this problem.

Requests for reprints to be made to Dr. P. A. Clark, consultant pathologist, Barnet General Hospital, Wellhouse Lane, Barnet, Herts.

REFERENCES

Cushing, I. E., and Miller, W. F. (1965). Respiratory Therapy, edited by P. Safar, p. 186. Oxford.

Gerarde, H. W. (1962). Industrial Hygiene and Toxicology, vol. 2, 2nd ed., edited by F. A. Patty, p. 1201.

Parker, C. A., and Barnes, W. J. (1960). Analyst, 85, 3.

\title{
Bronchial Carcinoma with Hypercalcaemia Simulating Cerebral Metastases
}

\author{
N. J. STRICKLAND,* M.A., M.B., B.CHIR.; A. M. BOLD, † M.A., B.M., B.CH.; W. E. MEDD,
}

The occurrence of hypercalcaemia in patients with a neoplasm without bony metastases has been recognized for some years. The symptoms and signs of hypercalcaemia may dominate the clinical picture. In particular, vomiting and mental disturbance might lead to an erroneous diagnosis of cerebral metastases, so that surgical removal of the primary growth is not attempted and a hopeless prognosis is given. Correct diagnosis with excision of the neoplasm may lead to symptomatic and biochemical recovery. The following case illustrates these points.

\section{Case Report}

A woman aged 54 complained of nausea and vomiting since an attack of diarrhoea three weeks previously. The vomiting occurred regardless of eating, and there was no abdominal pain or indigestion. She had also noticed lethargy, weakness, impairment of concentration and reasoning, and had had hiccups on and off for a month. She had always been constipated, and had passed urine once nightly for six months. She had lost 1 stone $(6.4 \mathrm{~kg}$.) in weight. She had had a cough since an episode of influenza eight months previously, and had smoked 30 cigarettes a day until 18 months before admission.

On examination there was moderately severe weakness of hip flexion and knee extension, and slight weakness of knee flexion on both sides. Her mental concentration was impaired. She sometimes used the wrong words, and her performance at "serial sevens" was impaired.

\section{Investigations}

The serum calcium and phosphorus results are given in the Table. Hb 13.9 g./100 ml. ; W.B.C. 9,200/cu. mm. ; E.S.R. $70 \mathrm{~mm}$. in one hour ; blood urea $28 \mathrm{mg} . / 100 \mathrm{ml}$. Plasma electrolytes: sodium

\footnotetext{
* Medical Registrar, Kingston Hospital, Kingston-upon-Thames, Surrey. † Senior Registrar in Biochemistry, Kingston Hospital, Kingston-uponThames, Surrey.

‡ Consultant Physician, Kingston Hospital, Kingston-upon-Thames,
} Surrey.
$144 \mathrm{mEq} / 1$. ; potassium $3.6 \mathrm{mEq} / 1$. ; chloride $94 \mathrm{mEq} / 1$. ; bicarbonate $34 \mathrm{mEq} / \mathrm{l}$. Liver-function tests: total bilirubin less than $0.5 \mathrm{mg} . / 100 \mathrm{ml}$; thymol turbidity 2.5 units ; cholesterol 260 mg./100 ml. ; alkaline phosphatase 11 K.A. units; S.G.O.T. 15 sigma units; S.G.P.T. 10 sigma units; serum albumin 4.9 g./100 $\mathrm{ml}$; serum globulin $2.9 \mathrm{~g} . / 100 \mathrm{ml}$.; electrophoresis: increase in $\alpha_{1}$ - and $\alpha_{2}$-globulin and mucoprotein.

Results of Serum Calcium and Phosphorus Determinations Before and

\begin{tabular}{|c|c|c|}
\hline Date & $\underset{(\mathrm{mg} . / 100 \mathrm{ml} .)}{\text { Serum Calcium }}$ & $\underset{\text { (mg./100 ml.) }}{\text { Serum Phoshorus }}$ \\
\hline $\begin{array}{c}3 / 9 / 64 \\
5 / 9 / 64 \\
7 / 9 / 64 \\
\text { PPreop. } \\
\text { P Postop. (4 p.m.) } \\
\text { Posto/64 } \\
\text { Midnight } \\
20 / 9 / 64 \\
21 / 9 / 64 \\
22 / 9 / 64 \\
25 / 9 / 64 \\
26 / 9 / 64 \\
28 / 9 / 64 \\
30 / 9 / 64 \\
2 / 10 / 64 \\
12 / 11 / 64 \\
15 / 2 / 65 \\
26 / 6 / 65 \\
24 / 8 / 65 \\
15 / 2 / 66\end{array}$ & $\begin{array}{c}16.4 \\
15.7 \\
16.9 \\
\text { Broken } \\
11.8 \\
11.3 \\
10.3 \\
10.4 \\
9.1 \\
9.1 \\
8.8 \\
9.1 \\
9.1 \\
9.5 \\
10.3 \\
10.1 \\
10.5 \\
10.0 \\
9.8\end{array}$ & $\begin{array}{l}\overline{2} \\
1.9 \\
2 \cdot 3 \\
3 \cdot 1 \\
2 \cdot 4 \\
2 \cdot 1 \\
1 \cdot 9 \\
3 \cdot 4 \\
3 \cdot 3 \\
3 \cdot 2 \\
4 \cdot 1 \\
3 \cdot 6 \\
4 \cdot 4 \\
4 \cdot 1 \\
4 \cdot 0\end{array}$ \\
\hline
\end{tabular}

Creatinine clearance $84 \mathrm{ml} . / \mathrm{min}$; urine calcium $136 \mathrm{mg} . / 24$ hours ; renal phosphate excretion index, +0.09 (normal $0 \pm 0.09-$ Nordin and Fraser, 1960).

The sputum showed numerous malignant cells, probably squamous in origin. Chest $x$-ray film (see Figure) showed a large tumour in the right upper lobe obstructing the upper-lobe bronchus with some deflation of the upper lobe. No lesion in the oesophagus, stomach, or duodenum was found on barium-meal examination. A radiological skeletal survey showed no bony metastases. $X$-ray examination of hands, feet, and teeth revealed moderate generalized decrease in bone density but no cortical erosions in the phalanges. There was some irregularity of the lateral parts of the lower radii and lower part of the humeri resembling hypertrophic pulmonary osteo- 
arthropathy. The periodontal membrane in the lower jaw was slightly ill-defined. Bronchoscopy (Miss M. C. Waterfall) showed pus coming from the right upper lobe.

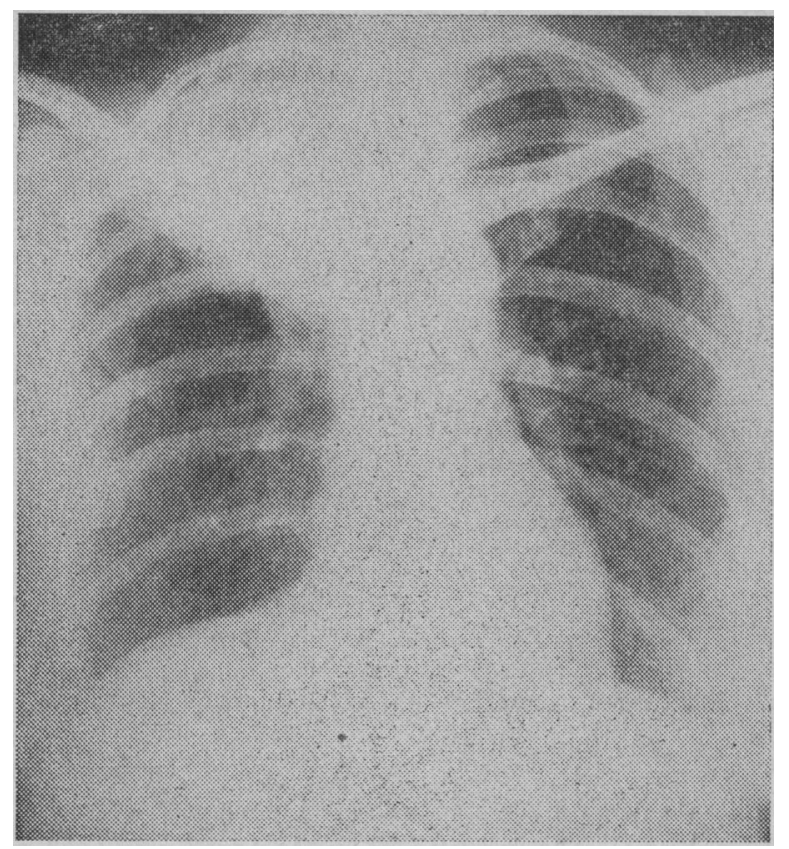

$X$-ray film of chest showing tumour in right upper lobe.

Lumbar puncture produced clear fluid at a pressure of $90 \mathrm{~mm} . \mathrm{H}_{2} \mathrm{O}$. There were 283 R.B.C.s/cu. mm., $60 \mathrm{mg}$. of protein per $100 \mathrm{ml}$, with excess of globulin, and $100 \mathrm{mg}$. of sugar per $100 \mathrm{ml}$. An electroencephalogram (E.E.G.) (Dr. D. Williams, Atkinson Morley's Hospital) was reported as showing very abnormal records, with recurrent phases of $1 \mathrm{c} / \mathrm{s}$ rhythms occurring equally throughout both hemispheres (possibly the result of high pressure), with evidence of extensive local damage also in the right temporal lobe, compatible with a tumour.

An electromyogram (E.M.G.) was reported by Dr. R. G. Willison (National Hospital, Queen Square) as follows: "Right quadriceps and tibialis anterior were sampled with a concentric needle electrode. There was no fibrillation, and the motor unit potentials on voluntary effort did not appear to be abnormal. On maximum voluntary effort a full pattern was seen, but there was striking fatigue after a few seconds and the pattern became rapidly reduced. Surface electrodes were placed over the left extensor digiti brevis. On stimulation of the anterior tibial nerve the muscle action potential measured over $5 \mathrm{mV}$ with normal latency. In conclusion the only abnormality is the rapid fatigue during voluntary effort."

\section{Course and Treatment}

Prednisone $20 \mathrm{mg}$. twice daily was given for only two days, when it was decided to remove the tumour. In the two weeks before operation her vomiting improved, though it did not stop. On 19 September 1964 she had a right upper lobectomy (Miss M. C. Waterfall). The specimen was reported on by Dr. M. E. A. Powell as follows: "Virtually the whole of the upper lobe was distorted by solid tumour, and histology showed that all but a small part of the base of the upper lobe was replaced by a nodular rounded growth. Microscopy showed an anaplastic carcinoma with a suggestion of a squamous pattern."

Her serum calcium returned to normal levels within 24 hours of the operation (see Table). Her mental state gradually became normal. The power in her legs improved, and three weeks after operation she had only slight weakness of left hip flexion and left knee flexion, all other movements being normal. Two months after operation there were no abnormal neurological signs. Nine months after operation she was symptom-free and there was no clinical or radiological evidence of recurrence of the neoplasm. She was back at her skilled clerical duties and was again solving a daily crossword which she had had to give up preoperatively. She was still symptomfree 18 months after operation.
A postoperative E.E.G. on 18 January 1965 (Dr. F. G. Campbell, Guy's Hospital) was reported on as follows: "Symmetrical $10 \mathrm{c} / \mathrm{s}$ alpha rhythm posteriorly, much fast activity which was widespread, and occasional runs of $8 \mathrm{c} / \mathrm{s}$ rhythm in the temporal areas. At rest, and more so during overbreathing, small sharp waves were seen in the right frontotemporal channels, and less often independently on the left, where low-voltage irregular theta waves also occurred. Thus the original gross abnormality of the E.E.G. had cleared up, but the second record showed a different type of abnormality suggestive of possible epileptogenic discharges in both temporal lobes." A postoperative E.M.G. on 22 July (Dr. R. G. Willison) was reported on as follows: "Right tibialis anterior and quadriceps were sampled with a concentric needle electrode. The appearances of motor units and the pattern on volition were normal. In particular, the pattern was well sustained, in marked contrast to the appearances preoperatively."

\section{Discussion}

The common clinical features of hypercalcaemia are mental disturbance, weakness, anorexia, and vomiting. Additional features may be too nonspecific to arouse much attention-for example, vague abdominal pains, constipation, mild polyuria, loss of weight, lethargy, drowsiness, or cardiac irregularities. Renal calculi, uraemia, and calcific or band keratitis seem to be uncommon in malignant cases, possibly because of the short duration of the hypercalcaemia. In the present case it seems likely that the mental symptoms, vomiting, and weakness of the legs were caused by the hypercalcaemia, though it is impossible to exclude an effect of the neoplasm on the nervous system mediated in other ways. Certainly the E.M.G. findings were similar to those in a patient with hypercalcaemia due to a parathyroid adenoma who was recently seen at this hospital.

In hypercalcaemia the E.E.G. may show diffuse alterations (Lehrer and Levitt, 1960 ; Krane and Roth, 1964) or suggest focal damage withoit presence of cerebral metastases. In the present case the E.E.G. before operation showed evidence of extensive local as well as diffuse damage. The E.E.G. after operation showed clearing of the original gross abnormality with residual, possibly epileptogenic, discharges in both temporal lobes. The E.M.G. before operation indicated rapid fatigue during voluntary effort. The E.M.G. after operation was normal. There is uncertainty about the significance of the changes in E.E.G. and E.M.G., which are described so that they can be compared with the findings in future cases.

\section{Possible Causes}

Of the possible causes of hypercalcaemia in this patient, vitamin-D overdosage, milk-alkali syndrome, and acute bone atrophy were excluded by the history. Serum electrophoresis and bone $x$-ray examination produced no evidence of multiple myeloma, though a bone-marrow examination was not made. There was no clinical or radiological evidence of sarcoidosis. The hypercalcaemia was thought to be caused either by the lung carcinoma or by coexisting primary hyperparathyroidism (Dent and Watson, 1964). The biochemical findings may be identical in these conditions, and distinction is often impossible. Estimation of plasma chloride has been claimed to be of help in distinguishing hyperparathyroidism from other causes of hypercalcaemia (Wills and McGowan, 1964). The presence of vomiting, however, as in this patient, might invalidate its usefulness. It was decided first to operate on the lung carcinoma. The fall in serum calcium to normal within 24 hours of the operation, and the persistently normal serum calcium and phosphorus in the next nine months, indicated that the lung carcinoma was the cause of the hypercalcaemia.

Bronchial carcinoma (squamous-cell type) is the commonest neoplasm to cause hypercalcaemia in the absence of bone metastases (Locks, 1962 ; Krane and Roth, 1964). In a series of 119 cases of carcinoma of the bronchus, Locks (1962) reported 
that $11 \%$ had a moderately raised serum calcium $(11.5-13 \mathrm{mg} . /$ $100 \mathrm{ml}$.) without symptoms of hypercalcaemia, but $50 \%$ of this group had radiologically demonstrable skeletal metastases ; $2 \%$ had a serum calcium around $16 \mathrm{mg} . / 100 \mathrm{ml}$., with classical symptoms of hypercalcaemia, and no skeletal metastases; and $9 \%$ of those with a normal serum calcium had skeletal metastases. Neoplasms in a wide variety of organs have also been reported to cause hypercalcaemia (Plimpton and Gellhorn, 1956 ; Watson, 1963 ; Krane and Roth, 1964).

Biochemical investigation characteristically shows a raised serum calcium, the serum inorganic phosphate tending to be low (Plimpton and Gellhorn, 1956). The proportion of ionized calcium is said to be normal, and there is no increase in the complexed fraction (Walser, 1962; Watson, 1963). Corticosteroids in some cases reduce hypercalcaemia (Lucas, 1960 ; Locks, 1962), but in others they have little or no effect (Krane and Roth, 1964). This suggests that the two groups have a different pathogenesis.

\section{Possible Mechanisms}

Several mechanisms for the hypercalcaemia have been proposed. Of these the production of a vitamin-D-like substance is unlikely. Successful treatment of the causative neoplasm is usually followed by a fall in the serum calcium to normal within four days, which would not be expected with cessation of production of a relatively long-acting substance such as vitamin D (Howard and Thomas, 1963). The second possible mechanism is that the tumour produces a substance, " $\mathrm{X}$," which stimulates the parathyroids (Stone et al., 1961 ; Krane and Roth, 1964). Supporting evidence is that some tumours are associated with chief cell hyperplasia of the parathyroid glands (Massaro and Owen, 1962 ; Krane and Roth, 1964), and subtotal parathyroidectomy has caused lowering of the serum calcium (Stone et al., 1961). Evidence against this view is that several authors have reported that the parathyroids are histologically normal, though this does not exclude hyperplasia (Plimpton and Gellhorn, 1956 ; Massachusetts General Hospital, 1961).

In addition, Goldberg et al. (1964) commented that the parathyroids at necropsy of one of their patients weighed much less than normal. The most probable mechanism is that the tumour produces a parathyroid-hormone-like substance as first suggested by Albright and Reifenstein (1948). Direct evidence in favour of this hypothesis has been provided by quantitative complement-fixation tests (Goldberg et al., 1964 ; Tashjian et al., 1964). These authors reported that extracts of primary and secondary carcinoma causing hypercalcaemia contain an antigen indistinguishable from parathyroid hormone. The concentration of this parathyroid-hormone-like substance has been much lower than that found in the parathyroid, but with large tumours the total amount has been comparable to the total in the parathyroid glands. It is possible, however, that there may be more than one mechanism for the hypercalcaemia in these patients.

In the present case the high serum calcium and low serum inorganic phosphate suggest increased production of a para- thyroid-hormone-like substance. In the absence of examination of the parathyroid glands and humoral assay of the tumour removed it is not possible to decide whether the tumour was producing a substance having the activity of parathyroid hormone or a "parathyrotropic" hormone.

The urine calcium in this patient was unusually low (136 mg./day) in relation to a serum calcium of about $16 \mathrm{mg} . / 100$ $\mathrm{ml}$. and a creatinine clearance of $84 \mathrm{ml} . /$ minute, though the patient's calcium intake may have been on the low side because of anorexia. Parathyroid hormone is thought to increase renal tubular reabsorption of calcium, but this action is normally insufficient to compensate for the increased filtered load of calcium in hypercalcaemia. Indeed, nearly all the reported cases of hypercalcaemia due to malignant disease have a raised urinary calcium (Plimpton and Gellhorn, 1956 ; Goldberg et al., 1964) though unexplained low excretion of urine calcium has been reported (Massachusetts General Hospital, 1961 ; Goldberg et al., 1964). Ionized and complexed calcium fractions were not measured in this patient, but the serum proteins were normal, so there is no reason to suspect that the proportion of ionized calcium was abnormal. The occasional finding of an unexpectedly low excretion of urinary calcium in patients with hypercalcaemia due to malignant disease is of interest, as it raises the possibility of another factor affecting urinary calcium excretion.

\section{Summary}

A case of hypercalcaemia from carcinoma of the bronchus without bony metastases is described in which some of the symptoms of hypercalcaemia resembled those of cerebral metastases. Removal of the tumour resulted in a rapid return of the serum calcium to normal, with relief of symptoms.

Our thanks are due to Dr. M. J. McArdle for his neurological assessment of the patient before and after operation; to Dr. B. W. Meade and Dr. M. E. A. Powell for advice on the biochemical and morbid anatomical aspects respectively; and to Dr. S. Holesh for advice on the radiology.

\section{REFERENCES}

Albright, F., and Reifenstein, E. C. (1948). The Parathyroid Glands and Metabolic Bone Disease. Baltimore.

Dent, C. E., and Watson, L. C. A. (1964). Brit. med. 7., 2, 218.

Goldberg, M. F., Tashian, A. H., Order, S. E., and Dammin, G. J. (1964). Amer. 7. Med., 36, 805.

Howard, J. E., and Thomas, W. C. (1963). Medicine (Baltimore), 42, 25.

Krane, S. M., and Roth, S. I. (1964). New Engl. Y. Med., 270, 898.

Lehrer, G. M., and Levitt, M. F. (1960). F. Mi Sinai Hosp., 27, 10

Locks, M. O. (1962). Y.-Lancet, 82, 165.

Locks, M. O. (1962). Y.-Lancel, 82, 163.

Massachusetts General Hospital (1961). Nero Engl. 7. Med., 264, 242.

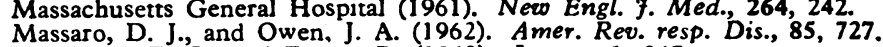

Nordin, B. E. C., and Fraser, R. (1960). Lancet, 1, 947 .

Plimpton, C. H., and Gellhorn, A. (1956). Amer. Y. Med., 21, 750.

Stone, G. E., Watterhouse, C., and Terry, R. (1961). Ann. iniern. Med., 54, 977.

Tashiian, A. H., Levine, L., and Munson, P. L. (1964). F. exp. Med., $119,467$.

Walser, M. (1962). 7. clin. Invest.; 41, 1454.

Watson, L. (1963). Postgrad. med. $7 ., 39,646$

Wills, M. R., and McGowan, G. K." (1964). Brit. med. F., 1, 1153. 